Document downloaded from:

http://hdl.handle.net/10251/62022

This paper must be cited as:

Garzón-Roca, J.; Sena-Cruz, JM.; Fernandes, P.; Xavier, J. (2015). Effect of wet-dry cycles on the bond behavior of concrete elements strengthened with NSM CFRP laminate strips. Composite Structures. 132:331-340. doi:10.1016/j.compstruct.2015.05.053.

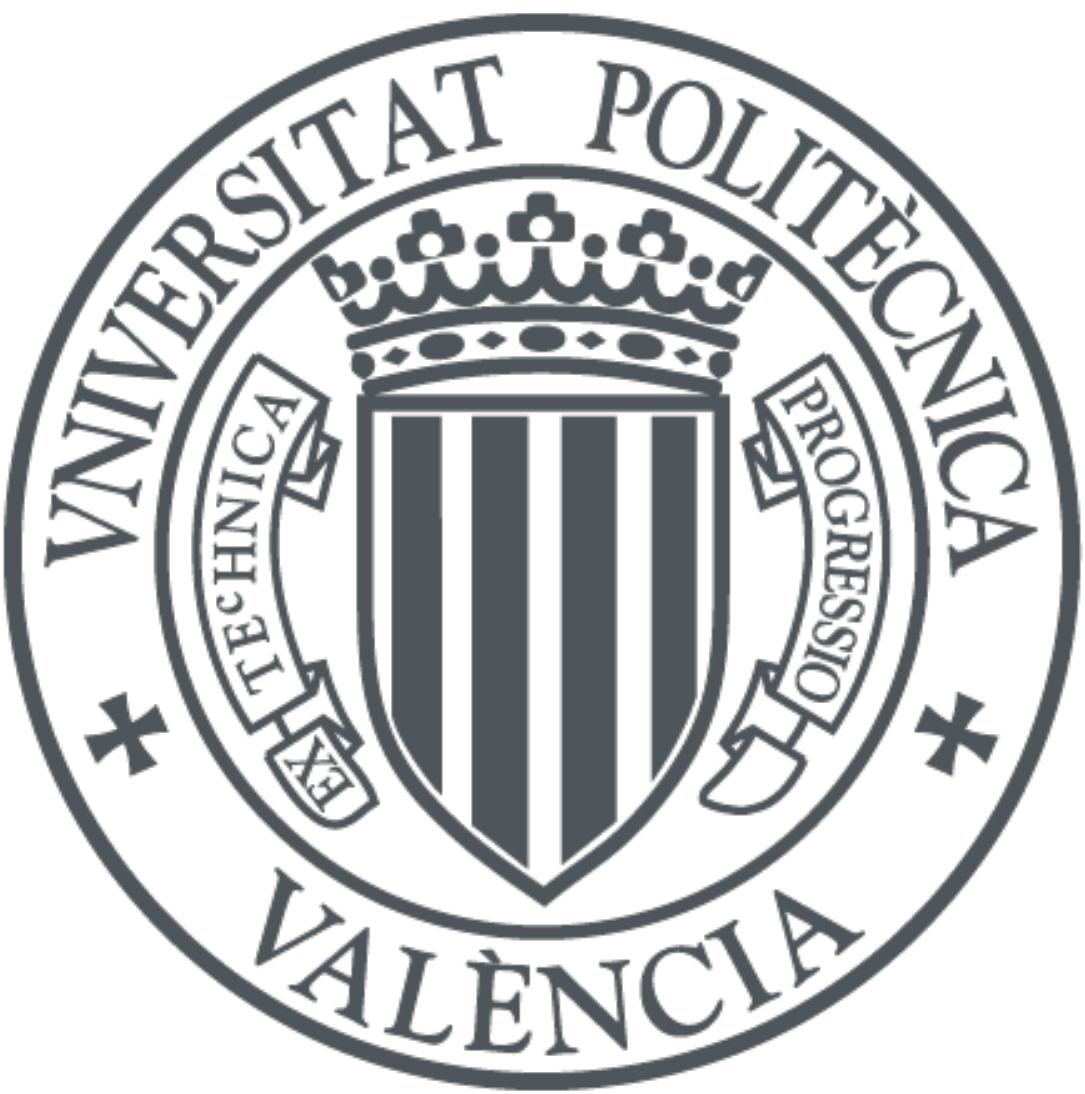

The final publication is available at

http://dx.doi.org/10.1016/j.compstruct.2015.05.053

Copyright Elsevier

Additional Information 


\title{
Effect of wet-dry cycles on the bond behavior of concrete elements strengthened with NSM CFRP laminate strips
}

\author{
Julio Garzón-Roca ${ }^{\mathrm{a}}$, José M. Sena-Cruz ${ }^{\mathrm{a}, *}$, Pedro Fernandes ${ }^{\mathrm{a}}$, José Xavier ${ }^{\mathrm{b}}$

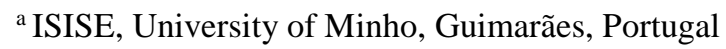 \\ ${ }^{\mathrm{b}}$ INEGI, Laboratory of Optics and Experimental Mechanics, FEUP, Porto, Portugal
}

\begin{abstract}
The near-surface mounted (NSM) strengthening technique is capable of effectively increase the bearing capacity of structural concrete elements. This technique which basically consists of placing FRP reinforcements inside small grooves cut in the concrete cover, has been widely investigated in terms of structural performance and ability to improve the flexural and shear behaviour of reinforced concrete beams and columns. However, little research has been carried out concerning to the NSM long-term performance and durability. Motivated by the need of increasing the knowledge on the expected durability of the NSM technique using CFRP laminates, this paper presents an experimental program in which direct pull-out tests are carried out for evaluating the bond behaviour of specimens aged through wet-dry cycles. A total of 30 specimens are tested, analysing the effect of the bond length, the groove width, the groove depth and the aging effect on the bond behaviour. Digital image correlation method is also used to identify the bond resistant mechanism developed in an element strengthened using NSM technique. Finally, using the experimental results, an analytical-numerical strategy is applied to establish the local bond stress-slip relationship.
\end{abstract}

Keywords: carbon fibre reinforced polymer; concrete; NSM; bonding; Digital Image Correlation; inverse analysis

\footnotetext{
* Corresponding author. Tel.: +351-253-510-200; fax: +351-253-510-217

E-mail address: jsena@civil.uminho.pt (J.M. Sena-Cruz)
} 


\section{Introduction}

The use of fibre reinforced polymer (FRP) materials to strengthen reinforced concrete elements has shown to be a useful and efficient option thanks to its good mechanical properties, lightness, resistance to corrosion, nonelectromagnetic properties and easy to install procedure [1-3]. One of the more recent developed strengthening technique with FRP materials is the near-surface mounted (NSM) method [2,4]. This technique involves the use of FRP materials placed into grooves opened on the concrete cover and filled with an epoxy adhesive, which is at the same time the bond agent between the FRP and the concrete. When compared NSM technique with the more traditional EBR (externally bonded reinforcement) technique some advantages arise [4] such as: the need of less work for the installation; the reduced probability of debonding; the simplicity to be anchored to adjacent member to prevent debond failures; the protection that the concrete cover gives and which reduces exposition to accidental impact and mechanical damage, fire, and vandalism; and, the unchanging in the aesthetics of the strengthened element.

Although some research has been conducted in the structural behaviour of NSM as a strengthening technique for increasing the flexural and shear behaviour of reinforced beams and columns as well as for strengthening beamcolumn joints [4-9], there is not enough knowledge about the NSM durability, a critical aspect that must be taken into account when designing a structural strengthening. According to Bulletin no. 40 of fib [10], common environmental conditions for studying the durability of a concrete element are wet-dry cycles in the presence of salts, freeze-thaw cycles, thermal and moisture cycles at fixed temperature, and cycles of salt fog.

Even though some research has been developed in related fields, such as the study of the bond degradation because of an aggressive environment between GFRP profiles and concrete [11], as mention above, research on NSM technique related to durability is rather limited. Burke [12] and Burke et al. [13, 14] carried out several experimental tests to investigate the performance of flexural NSM FRP strengthening systems applied to reinforced concrete slab strips, and subjected the specimens to three exposure conditions: constant room temperature $\left(+21^{\circ} \mathrm{C}\right)$, constant low temperature $\left(-26^{\circ} \mathrm{C}\right)$ and high temperatures $\left(+100^{\circ} \mathrm{C}\right.$ and $\left.+200^{\circ} \mathrm{C}\right)$; these tests showed debonding at epoxy/concrete interface to be the main failure mode, the non-affection of CFRP strips after being submitted to constant low temperatures, and the existence of significant losses, in terms of resistance, at elevated temperature, especially when considerably exceeding the glass transition temperature of the epoxy adhesive. Mitchell [15]

undertook freeze-thaw studies with flexural slabs strengthened with the NSM technique and some pull-out 
specimens; slabs and pull-out specimens were submitted to cycles in which temperature varied from $-30^{\circ} \mathrm{C}$ to $+20^{\circ} \mathrm{C}$; results showed a reduction in ultimate load of $2 \%$ for slabs and a $27 \%$ for pull-out specimens, being the predominant failure mode, in both cases, debonding at epoxy/concrete interface. Palmieri et al. [16] studied the bond behaviour between NSM FRP strips and concrete at elevated temperatures through double shear tests; temperatures ranged from $+20^{\circ} \mathrm{C}$ to $+100^{\circ} \mathrm{C}$, and results showed that when temperatures were higher than the glass transition temperature of the epoxy adhesive, failure modes changed from the splitting of adhesive to the FRP failure. Yu and Kodur [17] tested concrete specimens strengthened using NSM CFRP strips and rods and evaluated the bond strength in a temperature range of +20 to $+400^{\circ} \mathrm{C}$; results showed that bond strength decreased by nearly an $80 \%$ when temperature is over $+100^{\circ} \mathrm{C}$. Silva et al. [18] developed an experimental program using cubic pullout and slab specimens strengthened with NSM CFRP strips, and submitting these specimens to thermal cycles; temperature ranged from $-15^{\circ} \mathrm{C}$ to $+60^{\circ} \mathrm{C}$, and it was found that, in pull-out specimens, a slight improvement in terms of bond strength happens when applying thermal cycles; however, neither the failure mode nor slab behaviour were influence by the thermal action.

Pull-out tests are one of the most reliable ways of evaluating the bond performance presented in strengthening techniques. It important to note that the assessment of the bond performance is a very important aspect, since it governs both the ultimate load-carrying capacity and serviceability aspects, such as deformation and crack width $[19,20]$. In the last years several test setups have been proposed for analysing in detail the debonding phenomena. These configurations can be grouped in direct pull-out tests and beam pull-out tests. The former are more representative of end debonding and critical diagonal cracks while the latter are recommended to study intermediate crack debonding.

In the last years, the use of the Digital Image Correlation (DIC) method for capturing the displacement field of a structural element and studying its deformation has increased. DIC method provides full-field displacements on quasi-planar objects by maximizing the similarity of features in images corresponding to different deformation states [21]. Basically, DIC method consists of defining adjacent square subsets (defined in terms of number of pixels) in a reference image, normally, the underformed configuration, and applying a mathematical correlation between that reference image and other images (which capture the deformed configuration of the specimen study in several states) determine a displacement vector per subset; the surface of interest must have a speckled pattern, with an average size of the white-to-dark spots. Some advantages of DIC method [22] are the possibility of 
controlling an experiment, and/or registering data, by using optical means (i.e. contactless) as opposed to gauges or extensometers, which may be useful when dealing with aggressive, hot or corrosive environments, or in the case of studying soft solids for which gauges cannot be easily adapted; and, the option of registering data of an extensive region of the specimen, thus directly obtaining the displacement field of a structural element and facilitating the work with heterogeneous materials or structures where aspects such as strain localisations, damage localisation or crack initiation and propagation cannot be known a priori. Some examples of the successful uses of DIC method in FRP research includes the study of the bond behaviour between FRP and masonry [23] and direct determination of the cohesive stress transfer during debonding of FRP from concrete [24].

With the aim of increasing the knowledge on the durability of the strengthened concrete elements using the NSM technique, this paper presents an experimental program in which a series of pull-out tests are conducted to study the effect that wet-dry cycles in the presence of salts (which simulate the effect that an accelerated aging process) may have in the performance of this technique. Likewise, DIC method is used in one specimen to assess the distribution of the displacement and strains fields in concrete elements strengthened with the NSM technique. Finally, using the experimental results and applying an inverse analysis procedure, an analytical expression for the bond stress-slip relationship is obtained.

\section{Experimental Program}

\subsection{Specimens and test configuration}

Specimens tested consisted of concrete cubic blocks with $200 \mathrm{~mm}$ of edge, where a CFRP laminate with a $1.4 \mathrm{~mm}$ of thickness and a $10 \mathrm{~mm}$ of width was installed in a small groove located in the middle of one of their faces. The CFRP laminate was fixed to the concrete with an epoxy adhesive. It should be remarked that the CFRP was not attached along the total groove length, but only in a defined distance referred up to now as bond length, $L_{b}$. Due to the possibility of a premature failure of the specimen because of the possible formation of a fracture cone at the loaded end, this bond length started $100 \mathrm{~mm}$ from the top surface of the cubic block. In addition, a steel plate of $20 \mathrm{~mm}$ of thickness was placed on the top of the block and fixed to a rigid base by using M10 threaded rods fasten by a torque of $30 \mathrm{~N} \times \mathrm{m}$, so as to avoid any possible vertical displacement during pull-out test. Geometry of the specimens is shown in Fig. 1. Both $L_{b}$, groove width, $W_{g}$, and groove depth, $D_{g}$, were variable values dependent on the specimen tested. 
A total of 30 specimens distributed in thirteen series were tested, containing each series one, two or three specimens. Table 1 summarizes the experimental program carried out. All specimens belonging to one series had equal characteristics. For each set of the parameters $L_{b}, W_{g}$ and $D_{g}$, two series were considered: (i) one acting as reference, and kept in a climatic chamber at $20^{\circ} \mathrm{C}$ and $55 \%$ of relative humidity (REF specimens), and (ii) other exposed, after an epoxy curing period, to 90 wet-dry cycles (WD specimens); each cycle lasted 24 hours and involved wetting the specimens during 12 hours by immersion in water with $3 \%$ of $\mathrm{NaCl}$ at $20 \pm 1^{\circ} \mathrm{C}$, and drying the specimens at about $30 \pm 1^{\circ} \mathrm{C} . R E F$ specimens and its correspondent $W D$ specimens were tested at the same time. Hence, name given to each series follows the format "Lx_Wy_D $z_{-} X$ " with $x, y$ and $z$ the values of $L_{b}, W_{g}$ and $D_{g}$ respectively, and $X$ the keyword $R E F$ or $W D$ which points if the specimens were or not subjected to wet-dry cycles. Additionally, there existed a lonely specimen indicated with the keyword $R E F^{*}$; that specimen was identical to other $R E F$ specimens but it was tested 250 days after epoxy curing period (note that $R E F$ specimens were tested 90 days after epoxy curing period).

Pull-out force was applied to the CFRP laminate by a grip linked to an actuator. Between these two elements, a load cell with a static load carrying capacity of $200 \mathrm{kN}$ (linearity error of $< \pm 0.05 \%$ F.S.) and a LVDT were used to, respectively, register the force and control the test by displacement with a rate of $5 \mu \mathrm{m} / \mathrm{s}$. Relative displacement (slip) between concrete/epoxy and CFRP was recorded by placing another LVDT (range \pm 5 mm with linearity error of $\pm 0.09 \%$ F.S.) attached to the top part of the concrete block and in contact with the composite material.

For the case of the $R E F^{*}$ specimen, pull-out test was also monitored using Digital Image Correlation (DIC) method, placing an 8-bit Charged-Coupled Device (CCD) Baumer Optronic FWX20 digital camera equipped with a Nikon Zoom Nikkor AF 28-105mm f/3.5-4.5D IF lens. Components of the optical system as well as the measurement parameters used are listed in Table 2. Images acquisition frequency was $0.2 \mathrm{~Hz}$, and data treatment was performed by using GOM ARAMIS $®$ DIC-2D v6.02 software [25]. The lens aperture was set to f/11 for enhancing depth of field and avoiding diffraction effects, and lighting intensity and shutter time were adjusted in order to obtain a uniform illumination, avoid pixel saturation and prevent motion blur in the images during exposure. With this setup, the displacement and strain resolution associated were in the range of $2 \times 10^{-2}$ pixel and $0.02 \%$ respectively $[25,26]$. In order to create a local, random (isotropic) and contrasted grey level distribution in the target surface, concrete was firstly uniformed using iron paste and polished with 300-grit sandpaper, and then 
painted using a white matte background applied on the region of interest, followed by a spread distribution of black painting.

\subsection{Preparation of the specimens}

All the concrete specimens (blocks for pull-out tests and cylinders for the concrete mechanical characterization) were cast from a unique batch. Block specimens were cast as monolithic cubic elements without any groove. Once concrete was considered to have reached enough resistance (more than 28 days after casting), a simulated strengthened process of the NSM technique was carried out. The process involved cutting carefully the grooves, cleaning both the grooves and CFRP surfaces, prepare the epoxy adhesive and applied it along the bond length, keeping the CFRP laminates located at the middle of the groove. An epoxy curing period of 50 and 600 days for $D 25$ and $D 15$ series respectively was adopted. During the curing period, both $R E F$ and $W D$ specimens were kept in laboratory environment. WD specimens were subjected to wet-dry cycles only after this epoxy curing period had passed.

\subsection{Material characterization}

Cylindrical concrete specimens with $150 \mathrm{~mm}$ of diameter and $300 \mathrm{~mm}$ of height were tested at 28 days of age according to NP EN 12390-3:2009 [27] to evaluate the concrete compressive strength.

CFRP laminates used in pull-out specimens, with CFK 150/2000 trademark, were manufactured and supplied by S\&P® Clever Reinforcement Company, and consisted of unidirectional carbon fibres agglutinated by an epoxy vinylester resin, with a smooth external surface. The mechanical characterization of the tensile properties of these laminates was performed both in its original state, i.e. as received in the lab, and after having been subjected to the wet-dry cycles in the same conditions of pull-out specimens. Characterization tests were conducted according to ISO 527-5:1997 [28] adopting a displacement rate of $2 \mathrm{~mm} / \mathrm{min}$, and using a clip gauge mounted at middle region of the test specimen to determine the elastic modulus.

Similar to CFRP laminates, mechanical properties of epoxy adhesive were also evaluated both with and without exposing the material to the wet-dry cycles. Tests to find the tensile strength out were undertaken based on ISO 527-2:1993 [29] and a clip gauge mounted at middle region of the test specimen was used to determine the elastic modulus. 


\section{Results}

\subsection{Materials}

Concrete compressive tests showed an average compressive strength of $26.37 \mathrm{MPa}$, with a coefficient of variation $(\mathrm{CoV})$ of $4.0 \%$. Based on this result, concrete used in the pull-out specimens can be considered of medium-low resistance, which is expected to be the typical resistance to be found in an element susceptible of being strengthened using the NSM technique.

For the case of CFRP laminates, mechanical characterization tests carried out without subjecting the material to wet-dry cycles yielded a tensile strength of $2435.0 \mathrm{MPa}(\mathrm{CoV}=5.8 \%)$ and an elastic modulus of $158.0 \mathrm{GPa}$ $(\mathrm{CoV}=0.9 \%)$. After wet-dry cycles, mechanical properties of the CFRP material experienced a slight variation: tensile strength was found to be equal to $2281.7 \mathrm{MPa}(\mathrm{CoV}=5.8 \%)$, and elastic modulus resulted $154.7 \mathrm{GPa}$ $(\mathrm{CoV}=4.1 \%)$. Thus, the effect of the wet-dry cycles entailed a decrease of $6.3 \%$ for the tensile strength and $2.1 \%$ for the elastic modulus. It interesting to note that, in nearly all cases, the failure mode of the CFRP specimens occurred in explosive fashion because of a progressive rupture of the fibres at mid-height of the specimens.

For the epoxy adhesive, the obtained tensile strength was $17.33 \mathrm{MPa}(\mathrm{CoV}=5.8 \%)$, registering an elastic modulus of $6.35 \mathrm{GPa}(\mathrm{CoV}=5.8 \%)$, when the material was kept in lab environment not suffering any aging action. Conversely, these tensile properties varied to a tensile strength of $15.65 \mathrm{MPa}(\mathrm{CoV}=22.2 \%)$ and an elastic modulus of $5.87 \mathrm{GPa}(\mathrm{CoV}=17.1 \%)$ when the epoxy adhesive was exposed to the wet-dry cycles along with the pull-out test specimens. Consequently, a decrease of $9.7 \%$ and $7.6 \%$ for the tensile strength and modulus of elasticity respectively, took place. Likewise, the $\mathrm{CoV}$ of both properties significantly increased. Comparing these results with those obtained for the CFRP laminates, it is clear that degradation in the epoxy adhesive due to wet-dry cycles is much more important than in CFRP laminates.

\subsection{Pull-out tests}

The 30 pull-out specimens were tested by pulling the CFRP laminate out from the concrete block until the failure of the composite system occurred. During the whole tests both the pull-out force and the relative displacement between the concrete block and the CFRP laminate were registered. This relative displacement measured was the result of the sum of the slip between both materials and the elastic deformation of the CFRP laminate. Hence, for 
obtaining the slip, the elastic deformation had to be substrated from the total measurement. This process was made assuming, in all cases, a value for elastic modulus equal to that obtained in mechanical characterization of CFRP laminates without being subjected to the wet-dry cycles, $158 \mathrm{GPa}$ (note that the difference between this value and that obtained after the CFRP laminates were exposed to the cycles is only $2.1 \%$ which can be considered negligible). Fig. 2 shows typical pull-out force versus slip relationships. The results obtained are summarized in Table 3, which shows, for each specimen, the maximum load reached, $F_{\text {lmax }}$, and its corresponding loaded end slip, $s_{\operatorname{lmax}}$, as well as the maximum average bond stresses at CFRP-epoxy interface, $\tau_{l}$, and at the epoxy-concrete interface, $\tau_{2}$, and the failure mode. Values for $\tau_{1}$ and $\tau_{2}$ were computed according to $\tau_{1}=F_{\operatorname{lmax}} / L_{b} \times P_{C F R P}$ and $\tau_{2}=$ $F_{\text {lmax }} / L_{b} \times P_{\text {groove }}$, where $P_{C F R P}$ and $P_{\text {groove }}$ are the perimeter of the CFRP cross-section and the perimeter of the groove cross-section in contact with the adhesive, respectively. Moreover, for each series, average values along with their corresponding $\mathrm{CoV}$ value (place between parentheses) are shown.

Three different failure modes were identified (see Fig. 3): (i) concrete splitting, which affected a large area of concrete around the bonded region (C); (ii) CFRP failure at the loaded end section (F); and, (iii) debonding at the adhesive-laminate interface (D). It should be remarked that, despite being possible the debonding at the adhesiveconcrete interface, that never took place as expected, since the concrete groove surface was rougher than the external surface of the CFRP laminate.

For the case of $D 15$ specimens, where laminates were close to the concrete surface, concrete splitting was the main failure mechanism; however, when the groove width was increased, as in L60_W8_D15 series, concrete splitting did not take place, probably because this increment in the groove width resulted in lower bond stresses in the concrete-epoxy interface, which at the same time reduced stresses in concrete, thus avoiding splitting. Additional information about the resisting bond mechanics will be given further. In contrast with the $D 15$ series, debonding was the main failure mode identified in $D 25$ specimens, and it was the consequence of reaching a high bond stress (see $\tau_{l}$ and $\tau_{2}$ ) in the interfaces between concrete, epoxy and the laminate, and a lower stress state in concrete (note that the mobilized concrete area was higher due to a deeper grooves). It is interesting to mention that in general, debonding occurred without observing any significant crack in neither the epoxy nor the concrete. Eventually, CFRP failure was not so common and only occurred in one specimen (L90_W4_D25_REF_1); this could be related to the higher bond length and groove's depth which exists in this specimen, what prevented the debonding. 
Moreover, the effect of the wet/dry cycles marginally affected the failure mode: only in series L90_W4_D25 the failure mode changed from F/D to $\mathrm{C}$.

A general analysis of results shows that with the increase of the bond length, the maximum pull-out force increases; that means that the bond length of $60 \mathrm{~mm}$ (series L60) is less than the effective length for the studied system. Likewise, similar to that observed in failure mechanisms, the influence of groove depth is important: the increment displayed in the case of D15 series when bond length changes from $60 \mathrm{~mm}$ to $90 \mathrm{~mm}$ (L60_W4_D15 series against L90_W4_D15 series) gives an average value of a 23\%, while for D25 series (L60_W4_D25 series against L90_W4_D25 series), this average increment is only a $12 \%$.

Fig. 4 shows the effect of wet-dry cycles on the series tested. In this graph, the relative difference, in terms of percentage, between the mean values of $F_{\text {lmax }}$ obtained for $R E F$ specimens and for $W D$ specimens of same characteristics (i.e. same $L_{b}, W_{g}$ and $D_{g}$ ) are depicted. As can be seen, in the case of $D 15$ series, the ageing effect produced by the wet-dry cycles leads to decreasing the maximum pull-out force bearable by the specimen; this effect is much higher in the case of L60_W4_D15 series where reduction is around 14\%. When bond length is increased (L90_W4_D15 series), the aging effect is reduced in more than a half, what reveals that having a bond length closer to the effective length has also a very beneficial effect in terms of aging. Consequently, assuring an appropriate bond length in the NSM technique should be a crucial objective when designing this kind of strengthening. With regard to the influence of the groove width, it is observed that L60_W8_D15 series the effect of wet-dry cycles had a small influence (less than 3\%) in the maximum pull-out force. This could be put down to the fact that in these specimens there is a $50 \%$ more volume of epoxy adhesive surrounding the CFRP laminate than in the case of L60_W4_D15 series, which makes this "extra" amount of adhesive protect the adhesivelaminate interface from the degradation produced by the wet-dry cycles.

On the other hand, in the case of D25 specimens, a confusing behaviour is observed: both for series L60_W4_D25 and L90_W4_D25 the wet-dry cycles had a positive effect, increasing the value of $F_{\text {lmax }}$ achieved. However, this can be explained because of the epoxy curing period of $D 25$ series which was 150 days, unlike $D 15$ series which had a curing period of 600 days. Consequently, it may be possible that the epoxy curing period for D25 series was not enough, and as a result, the wet-dry cycles may have contributed to an accelerate curing of the epoxy adhesive. Conversely, this positive effect was not experimented in L60_W8_D25 series, where the aging process cause a 
very small decrease (barely a $1.3 \%$ ) in $F_{l \max }$. Reason of this phenomena can be attributed, similar to what has been commented above for L60_W8_D15, to the great amount of epoxy in the specimen, which resulted, not only in preventing degradation in the adhesive-laminate, but in decreasing the curing effect of the wet-dry cycles in epoxy also.

\subsection{Comparison with other studies}

The obtained results were compared with those referred in the literature. Sena-Cruz et al. [30] subjected a series of concrete slabs strengthened with CFRP laminate strips using the NSM technique to several environmental conditions, including wet-dry cycles, during 360 and 720 days. Results showed that after 360 days of being submitted to wet-dry cycles, specimens experimented an increment in load capacity of around a 7\%; however, after 720 days, a reduction of a $7 \%$ occurred. Silva et al. [31] subjected some beam pull-out specimens to wet-dry cycles also during 360 and 720 days, obtaining similar results; hence, after 360 day of submitting specimens to wet-dry cycles, load capacity increases about a $16 \%$, while the effect for 720 days was experimenting a reduction of nearly a 7\%. Goebel [32] studied the effect of bond degradation between concrete and CFRP strips in the NSM technique due to several environmental conditions, performing several pull-out tests. This research also tested the effect of using different types of epoxy adhesives in the interface concrete-CFRP. For the case of wet-dry cycles, it was found that after submitting specimens to this conditions an average gain of $12 \%$ in the strength was observed.

The obtained values in the previous investigations are close to that registered for the specimens presented in this work. As was the case of the specimens tested in the present paper, the probable reason for having an increment in the load capacity in some results may be the consequence of an insufficient epoxy curing period. For this kind of specimens, results obtained in this paper (series L60_W4_D25 and L90_W4_D25) gave similar values (11.4\% and $7.7 \%$ respectively) to that obtained by the other authors. Regarding to the specimens of Sena-Cruz et al. [30] and Silva et al. [31] tested after 720 days, these specimens suffered bond degradation due to the wet-dry cycles, meaning that epoxy cured period was less than that time. That effect is similar to what was observed in series L60_W4_D15, L60_W8_D15 and L90_W4_D15 of this paper, in which epoxy cured period was extended to 600 days. 


\subsection{DIC outputs}

As mention in sections above, $R E F^{*}$ specimen was also monitored by using the DIC method. A comparison between the measured loaded end slip using the LVDT and the DIC method is depicted in Fig. 5, showing that the overall behaviour is very similar both using DIC method and an LVDT, and thus validating DIC results. The use of DIC method enables to obtain much more information than using a simple LVDT, especially in terms of displacements and deformations in any point of the studied region. Fig. 6 presents, for different levels of pull-out force and for both directions $x$ and $y$ (being $x$ the direction of the pull-out force which is applied at the left side of the picture), the displacements $\left(U_{x}\right.$ and $\left.U_{y}\right)$ and the strains $\left(\varepsilon_{x}\right.$ and $\left.\varepsilon_{y}\right)$, as well as the distortional field $x y\left(\gamma_{x y}\right)$ registered. These images show that displacements $U_{x}$ and $U_{y}$ are symmetrical in relation to the longitudinal axis of the laminate ( $x$ direction), being higher in the groove region. Magnitude of $U_{x}$ results to be 10 times higher than $U_{y}$, and its maximum value (around $0.2 \mathrm{~mm}$ ) is located in the debonding region. In the case of strains, maximum values when achieving the maximum pull-out force occurred at the vicinity of the free end region, being the strain levels of $\varepsilon_{x}$ and $\varepsilon_{y}$ very similar. Strain images and the distortional field also reveal and confirm that diagonal compressive forces, or struts, are developed in the adhesive and then transferred to concrete, producing a "fishspine" crack pattern [33], as schematically depicted in Fig. 7a, and which was also observed in the results of the pull-out specimens after being examine by using an optical microscope (Fig. 7b).

\section{Numerical Simulations}

\subsection{Local bond slip and pullout load-slip relationship}

The local bond phenomena between two materials (in this case, CFRP laminate and the epoxy adhesive) is normally characterised by a second order differential equation. This expression may be established in terms of forces [34,35] or, as is the case of this paper, may be derived in terms of slip [19,36]. In the following lines, a brief overview of the analytical formulation used in this paper is presented, being possible to find more details elsewhere [19,37]. It is interesting to note that the adopted analytical model has previously shown a good predictive performance on modelling bond between CFRP and adhesive in other investigations on the NSM technique for strengthening concrete [37] and glulam [20] materials.

The equilibrium of an infinitesimal length $d x$ of a CFRP laminate place into a concrete groove filled with an epoxy adhesive can be written as:

$$
\sigma_{f} \cdot t_{f} \cdot w_{f}+2 \cdot \tau \cdot w_{f} \cdot d x=\left(\sigma_{f}+d \sigma_{f}\right) t_{f} \cdot w_{f}
$$


being $\sigma_{f}$ the normal stress, $t_{f}$ and $w_{f}$ the CFRP laminate thickness and the width, and $\tau=\tau(s(x))$ the bond stress on the contact surface between the CFRP and the epoxy adhesive, which is a function of the slip, $s(x)$, registered between both components. If it is assumed that the CFRP has a linear behaviour, then normal stress is directly proportional to normal strain $\varepsilon_{f}$, so Eq. (1) can be rewritten as:

$$
\tau=\frac{E_{f} \cdot t_{f}}{2} \frac{d \varepsilon_{f}}{d x}
$$

where $E_{f}$ represents the CFRP elastic modulus. Neglecting the deformability of both the concrete and the adhesive in the slip deformation, then $\varepsilon_{f}=d s / d x$, so Eq. (3) is obtained:

$$
\frac{d^{2} s}{d x^{2}}=\tau \frac{2}{E_{f} \cdot t_{f}}
$$

Eq. (3) is the second order differential equation that governs the local bond phenomena of the CFRP laminateadhesive interface. Eq. (3) can be solved once the local bond stress relationship $\tau$-s has been established. In this paper, this relationship has been defined by Eq. (4), which has only four parameters: $\tau_{m}, s_{m}, \alpha$ and $\alpha^{\prime}$; the former two are the bond stress and its corresponding slip, while the latter two are parameters which define the shape of the curves.

$$
\tau(s)= \begin{cases}\tau_{m} \cdot\left(\frac{s}{s_{m}}\right)^{\alpha} & \text { if } s \leq s_{m} \\ \tau_{m} \cdot\left(\frac{s}{s_{m}}\right)^{-\alpha^{\prime}} & \text { if } s>s_{m}\end{cases}
$$

\subsection{Numerical procedure}

In order to solve Eq. (3) taking into account local bond stress relationship $\tau$-s of Eq. (4), a numerical algorithm was developed. This algorithm broadly consist of obtaining the four parameter, $\tau_{m}, s_{m}, \alpha$ and $\alpha$ ', by inverse analysis from experimental results. For that, a set of parameters were defined, and based on them, the Eq. (3) was solved using the relation of Eq. (4), following the schemes showed in Fig. 8, and considering the boundary conditions of free and loaded ends showed in Eq. (5) (where $N$ represents the pull-out force experimentally measured). That led to obtain a numerical pull-out force versus slip curve which was compared with the experimental one, computing the error as the existent area between both curves. When the error was considered high, a new set of parameters was defined and the process was repeated. More details of this algorithm can be found elsewhere [19,37]. 


$$
x=0 \Rightarrow\left\{\begin{array}{l}
s(0)=s_{f} \\
N(0)=0 \\
\varepsilon_{f}(0)=0
\end{array} ; \quad x=L_{b} \Rightarrow\left\{\begin{array}{l}
s\left(L_{b}\right)=s_{l} \\
N\left(L_{b}\right)=\bar{N} \\
\varepsilon_{f}\left(L_{b}\right)=\bar{N} /\left(E_{f} \cdot A_{f}\right)
\end{array}\right.\right.
$$

\subsection{Numerical results}

The numerical procedure described above was applied to the specimens experimentally tested to obtain their local bond stress-slip relationship, which translates into finding the appropriate values of the parameters $\tau_{m}, s_{m}, \alpha$ and $\alpha^{\prime}$. For each series, the average relationship between the loaded end slip and the pull-out force was used to calibrate the relationship. For the CFRP elasticity modulus, a value of $158 \mathrm{GPa}$ was used, the same value as that assumed in experimental test to compute the elastic deformation of the laminate.

Numerical results for each series experimentally tested are shown in Table 4, including, besides the value of parameters $\tau_{m}, s_{m}, \alpha$ and $\alpha$, the normalized error, Err (the error obtained as the area between the experimental and the numerical curves, divided by the area of the experimental curve), and the error ratios in the maximum pull-out force $\left(F_{l, \text { num }} / F_{l, \text { exp }}\right)$ and in the loaded end slip value corresponding to the maximum pull-out force $\left(s_{l, \text { num }} / s_{l, \text { exp }}\right)$. As can be observed, normalized error is acceptable, achieving a mean value of $6.76 \%$. Likewise, in all cases, the maximum value for ratio $F_{l, n u m} / F_{l, \text { exp }}$ is less than a $1.15 \%$, which shows the good precision on the estimation of the maximum pull-out load. For the case of ratio $s_{l, \text { num }} / s_{l, \text { exp }}$, also good values were achieved. Fig. 9 presents a graphical comparison between some of the experimental and numerical pull-out force versus slip curves, showing a good fit between experimental and numerical results. Therefore, from the results obtained, it can be concluded that the numerical inverse analysis carried out is able to predict with good accuracy the pull-out force versus slip relationships of the specimens tested. The average bond stress of all series is equal to $20.8 \mathrm{MPa}$. This value is in agreement with value obtained in other studies, e.g. [19]. As expected, $\tau_{m}$ is commanded by the maximum pull-out force obtained experimentally. A large variation is obtained for the parameters $\alpha$ and $\alpha^{\prime}$. This behaviour is related to the fact that these parameters control the shape of the pull-out force versus slip.

\section{Conclusions}

This work has presented an experimental study through direct pull-out tests on the durability of the near surface mounted (NSM) strengthening technique under wet-dry cycles. The bond performance between CFRP laminates, epoxy adhesive and concrete has been investigated by testing a total of 30 specimens to analyse the influence of the bond length, the groove depth, the groove width and the strengthening application age. The following variables 
were adopted in the present study to evaluate the bond performance: bond length, groove width, groove depth and aging effect (wet-dry cycles).

Failure modes observed in the specimen tested included concrete splitting, CFRP laminates failure and debonding at adhesive/laminate interface, being the first one more typical in specimens with grooves of $15 \mathrm{~mm}$ depth and the last one common of specimens with grooves of $25 \mathrm{~mm}$ depth.

Obtained results have shown a decrease of around a $12 \%$ in the maximum pull-out force due to the wet-dry cycles for the specimens series with grooves of a depth equal to $15 \mathrm{~mm}$ and a width of $4 \mathrm{~mm}$, being the bond length of $60 \mathrm{~mm}$; however, when the bond length increased to $90 \mathrm{~mm}$, the effect of the wet-dry cycles showed a reduction of more than a 50\%; likewise, when groove depth was increased to $8 \mathrm{~mm}$, the decrement in the pull-out force was reduced to very low values. Conversely, for specimens with grooves of $25 \mathrm{~mm}$, results showed an increase of around $10 \%$ in pull-out force when specimens were subjected to wet-dry cycles; this behaviour could be the consequence of a low epoxy curing period applied in this specific specimens. Nevertheless, specimens with grooves of a width of $8 \mathrm{~mm}$ experimented a slight decrement in pull-out maximum force of around the $1 \%$, being this value obtained similar to that registered for the case of the specimens with $15 \mathrm{~mm}$ of groove depth with $8 \mathrm{~mm}$ of groove width. Results have been compared with other investigations carried out previously by other authors, showing a good agreement with them.

Digital image correlation (DIC) method has been used to analyse the displacements, strains and distortional field in one of the pull-out specimen tested. DIC method has revealed that maximum values of strains occurred at the vicinity of the free end region, and has shown that the bond resistant mechanism involved the development of diagonal compressive struts in the adhesive which transfer the force to concrete, resulting in the characteristic "fish-spine" crack pattern.

Finally, based on the experimental test results, a numerical analysis has been undertaken to establish the local bond stress-slip relationship of the specimens tested. From this numerical analysis, an average bond strength of 20.8 MPa was obtained. 


\section{Acknowledgements}

This work was supported by FEDER funds through the Operational Program for Competitiveness Factors COMPETE and National Funds through FCT - Portuguese Foundation for Science and Technology under the project CutInDur PTDC/ECM/112396/2009. The third author acknowledge the grant SFRH/BD/80338/2011 provided by FCT. Finally, the authors also like to thank all the companies that have been involved supporting and contributing for the development of this study, mainly S\&P Clever Reinforcement Ibérica Lda. and SECIL.

\section{References}

[1] Bakis CE, Bank LC, Brown VL, Cosenza E, Davalos JF, Lesko JJ, et al. Fiberreinforced polymer composites for construction-state-of-the-art review. J Compos Constr 2002;6(2):73-87.

[2] ACI. Guide for the design and construction of externally bonded FRP systems for strengthening concrete structures - ACI 440F. Report ACI 440.2R-08. American Concrete Institute, Farmington Hills, USA, 2008.

[3] FIB. Externally bonded FRP reinforcement for RC structures. Bulletin 14. Lausanne, 2001.

[4] De Lorenzis L, Teng JG. Near-surface mounted FRP reinforcement: an emerging technique for strengthening structures. Compos Part B 2007;38(2):119-43.

[5] El-Hacha R, Rizkalla SH. Near-surface-mounted fiber-reinforced polymer reinforcements for flexural strengthening of concrete structures. ACI Struct J 2004;101(5):717-26.

[6] Barros JAO, Fortes AS. Flexural strengthening of concrete beams with CFRP laminates bonded into slits. J Cem Concr Compos 2005;27(4):471-80.

[7] Barros JAO, Dias SJE. Near surface mounted CFRP laminates for shear strengthening of concrete beams. J Cem Concr Compos 2006;28(3):276-92.

[8] Sena-Cruz JM, Barros JAO, Coelho MRF, Silva LFFT. Efficiency of different techniques in flexural strengthening of RC beams under monotonic and fatigue loading. Constr Build Mater 2012;29:175-82.

[9] Barros JAO, Varma RK, Sena-Cruz JM, Azevedo AFM. Near surface mounted CFRP strips for the flexural strengthening of RC columns: Experimental and numerical research. Eng Struct 2008;30(12):3412-25.

[10] FIB. FRP reinforcement in RC structures. Bulletin No. 40. Lausanne, 2007.

[11] Mendes PJD, Barros JAO, Sena-Cruz J, Teheri M. Influence of fatigue and aggressive exposure on GFRP girder to SFRSCC deck all-adhesive connection. Compos Struct 2014;110:152-62.

[12] Burke PJ. Low and High Temperature Performance of Near Surface Mounted FRP Strengthened Concrete Slabs. Master of Science, Queen's University, 2008. 
[13] Burke PJ, Bisby L, Green M. Performance of NSM FRP strengthened concrete slabs at low temperatures. Fourth Int. Conf. on FRP Composites in Civil Engineering (CICE 2008), International Institute for FRP in Construction (IIFC), Winnipeg, Manitoba, Canada, 2008.

[14] Burke PJ, Bisby L, Green M. Effects of elevated temperature on near surface mounted and externally bonded FRP strengthening systems for concrete". Cem Concr Compos 2013; 35(1):190-9.

[15] Mitchell PA. Freeze-Thaw and Sustained Load Durability of Near Surface Mounted FRP Strengthened Concrete. Master Thesis, Queen’s University, 2010

[16] Palmieri A, Matthys S, Taerwe L. Influence of high temperature on bond between NSM FRP bars/strips and concrete. Proceedings of the 10th international symposium of the fiberreinforced polymer reinforcement for reinforced concrete structures, 2011.

[17] Yu B, Kodur V. Effect of high temperature on bond strength of near-surface mounted FRP reinforcement. Compos Struct 2014;110:88-97.

[18] Silva P, Fernandes P, Sena-Cruz J, Azenha M, Barros JAO. Behaviour of concrete elements strengthened with Near Surface Mounted CFRP strips under thermal cycles. Seventh Int. Conf. on FRP Composites in Civil Engineering (CICE 2014), International Institute for FRP in Construction (IIFC), Vancouver, 2014.

[19] Sena-Cruz JM, Barros JAO. Modeling of bond between near-surface mounted CFRP laminate strips and concrete. Comput Struct J 2004;82:1513-21.

[20] Sena-Cruz JM, Jorge M, Branco JM, Cunha VMCF. Bond between glulam and NSM CFRP laminates. Constr Build Mater 2013;40:260-69.

[21] Pan B, Qian K., Xie H, Asundi A. 2009. Two dimensional digital image correlation for in-plane displacement and strain measurement: a review. Meas. Sci. Technol 2009;20(6):1-18.

[22] Hild F, Roux S. Digital Image Correlation: from Displacement Measurement to Identification of Elastic Properties - a Review. Strain 2006;42:69-80.

[23] Ghiassi B, Xavier J, Oliveira DV, Lourenço PB. Application of digital image correlation in investigating the bond between FRP and masonry. Compos Struct 2013;106:340-9.

[24] Carloni C, Subramaniam KV. Direct determination of cohesive stress transfer during debonding of FRP from concrete. Compos Struct 2010;93:184-92.

[25] GOM. ARAMIS commercial software. <http://www.gom.com/>

[26] Xavier J, de Jesus AMP, Morais JJL, Pinto JMT. Stereovision measurements on evaluating the modulus of elasticity of wood by compression tests parallel to the grain. Constr Build Mater 2012;26 (1):207-15. 
[27] NP EN 12390-3:2009. Testing hardened concrete. Part 3: Compression resistance of test specimens. Portuguese Institute for Quality, Lisbon; 2009. [in Portuguese]

[28] ISO 527-5. Plastics - determination of tensile properties - Part 5: test conditions for unidirectional fibrereinforced plastic composites. International Organization for Standardization (ISO); 1997.

[29] ISO 527-2. Plastics - determination of tensile properties - Part 2: test conditions for molding and extrusion plastics. International Organization for Standardization (ISO); 1993.

[30] Sena-Cruz J, Silva P, Fernandes P, Azenha M, Barros J, de Sousa C, Castro F, Teixeira T. Creep Behavior of Concrete Elements Strengthened with NSM CFRP Laminate Strips under Different Environmental Conditions. FRPRCS11-11th International Symposium on Fiber Reinforced Polymer for Reinforced Concrete Structures, Guimarães, 2013.

[31] Silva P, Fernandes P, Sena-Cruz J, Azenha M, Barros J. Creep Behaviour and Durability of Concrete Elements Strengthened with NSM CFRP Strips. The 7th International Conference on FRP Composites in Civil Engineering, Vancouver, 2014.

[32] Goebel JH. Design and Environmental Performance of Near-Surface Mounted Carbon Fiber Reinforced Polymer Strips for Shear Strengthening Reinforced Concrete Bridge Girders. Master Thesis, School of Civil and Construction Engineering, Oregon State University, 2012.

[33] Sena-Cruz JM, Barros JAO. Bond Between Near-Surface Mounted Carbon-Fiber-Reinforced Polymer Laminate Strips and Concrete. J Compos Constr 2004;8(6):519-27.

[34] Sujivorakul C, Waas AM, Naaman A. Pullout response of a smooth fiber with an end anchorage. Eng Mech 2000;126(9):986-93.

[35] Banholzer B, Brameshuber W, Jung W. Analytical simulation of pull-out tests - the direct problem. Cem Concr Compos 2005;27:93-101.

[36] Focacci F, Nanni A, Bakis C. Local bond-slip relationship for FRP reinforcement in concrete. Compos Constr 2000;4(1):24-31.

[37] Sena-Cruz JM, Barros JAO, Gettu R, Azevedo AFM. Bond behavior of near surface mounted CFRP laminate strips under monotonic and cyclic loading. Compos Constr 2006;10(4):295-303. 


\section{$\underline{\text { List of Tables }}$}

Table 1: Experimental program

Table 2: Optical system components and measurements parameters

Table 3: Pull-out tests results

Table 4: Numerical results 
Table 1: Experimental program

\begin{tabular}{lcccc}
\hline Series & $L_{b}(\mathrm{~mm})$ & $W_{g}(\mathrm{~mm})$ & $D_{g}(\mathrm{~mm})$ & No. of specimens \\
\hline L60_W4_D15_REF & 60 & 4 & 15 & 3 \\
L60_W4_D15_WD & 60 & 4 & 15 & 3 \\
L60_W8_D15_REF & 60 & 8 & 15 & 2 \\
L60_W8_D15_WD & 60 & 8 & 15 & 2 \\
L90_W4_D15_REF & 90 & 4 & 15 & 2 \\
L90_W4_D15_WD & 90 & 4 & 15 & 2 \\
\hline L60_W4_D25_REF & 60 & 4 & 25 & 3 \\
L60_W4_D25_WD & 60 & 4 & 25 & 2 \\
L60_W8_D25_REF & 60 & 8 & 25 & 2 \\
L60_W8_D25_WD & 60 & 8 & 25 & 2 \\
L90_W4_D25_REF & 90 & 4 & 25 & 3 \\
L90_W4_D25_WD & 90 & 4 & 25 & 1 \\
\hline L60_W4_D25_REF* & 60 & 4 & 25 & 2 \\
\hline
\end{tabular}


Table 2: Optical system components and measurements parameters

\begin{tabular}{ll}
\hline CCD Camera & \\
\hline Model & Baumer Optronic FWX20 (8 bits, 1624×1236 pixels) \\
Shutter time & $3 \mathrm{~ms}$ \\
Frequency & $0.2 \mathrm{~Hz}$ \\
\hline Lens & \\
\hline Model & Nikon Zoom Nikkor AF 28-105mm f/3.5-4.5D IF \\
Aperture & $f / 11$ \\
Lighting & Raylux 25 white-light LED \\
Working distance & $470 \mathrm{~mm}$ \\
Conversion factor & $0.033 \mathrm{~mm} /$ pixel \\
\hline ARAMIS DIC-2D software \\
\hline Facet size & $15 \times 15$ pixels \\
Step size & $15 \times 15$ pixels \\
Strain step & 7 subsets \\
Measuring points & $15 \times 15$ pixels \\
\hline
\end{tabular}


Table 3: Pull-out tests results

\begin{tabular}{|c|c|c|c|c|c|}
\hline Specimen & $F_{\operatorname{lmax}}(\mathrm{kN})$ & $s_{\operatorname{lmax}}(\mathrm{mm})$ & $\tau_{l}(\mathrm{MPa})$ & $\tau_{2}(\mathrm{MPa})$ & $\begin{array}{l}\text { Failure } \\
\text { mode }\end{array}$ \\
\hline L60_W4_D15_REF_1 & 29.1 & 0.47 & 21.3 & 14.3 & $\mathrm{C}$ \\
\hline L60_W4_D15_REF_2 & 29.7 & 0.75 & 21.7 & 14.6 & $\mathrm{C}$ \\
\hline L60_W4_D15_REF_3 & 28.2 & 0.60 & 20.6 & 13.8 & $\mathrm{C}$ \\
\hline L60_W4_D15_REF & $29.0(2.6 \%)$ & $0.61(23.1 \%)$ & 21.2 & 14.2 & - \\
\hline L60 W4 D15 WD 1 & 25.9 & 0.47 & 18.9 & 12.7 & $\mathrm{C}$ \\
\hline L60_W4_D15_WD_2 & 23.7 & 0.33 & 17.3 & 11.6 & $\mathrm{C}$ \\
\hline L60_W4_D15_WD_3 & 26.5 & 0.31 & 19.4 & 13.0 & $\mathrm{C}$ \\
\hline L60_W4_D15_WD & $25.4(5.8 \%)$ & $0.37(23.6 \%)$ & 18.5 & 12.4 & - \\
\hline L60_W8_D15_REF_1 & 26.9 & 0.72 & 19.7 & 11.8 & $\mathrm{D}$ \\
\hline L60_W8_D15_REF_2 & 26.7 & 1.03 & 19.5 & 11.7 & $\mathrm{D}$ \\
\hline L60_W8_D15_REF & $26.8(0.5 \%)$ & $0.88(25.05 \%)$ & 19.6 & 11.8 & - \\
\hline L60_W8_D15_WD_1 & 25.9 & 0.80 & 19.0 & 11.4 & $\mathrm{D}+\mathrm{C}$ \\
\hline L60_W8_D15_WD_2 & 26.2 & 0.82 & 19.2 & 11.5 & $\mathrm{D}+\mathrm{C}$ \\
\hline L60_W8_D15_WD & $26.1(0.8 \%)$ & $0.81(1.7 \%)$ & 19.1 & 11.5 & - \\
\hline L90_W4_D15_REF_1 & 37.8 & 0.99 & 18.4 & 12.3 & $\mathrm{C}$ \\
\hline L90_W4_D15_REF_2 & 35.0 & 1.12 & 17.1 & 11.4 & $\mathrm{C}$ \\
\hline L90_W4_D15_REF & $36.4(5.4 \%)$ & $1.06(8.7 \%)$ & 17.8 & 11.9 & - \\
\hline L90 W4 D15 WD 1 & 34.5 & 0.48 & 16.8 & 11.3 & $\mathrm{C}$ \\
\hline L90_W4_D15_WD_2 & 34.2 & 0.64 & 16.7 & 11.2 & $\mathrm{C}$ \\
\hline L90_W4_D15_WD & $34.4(0.6 \%)$ & $0.56(20.2 \%)$ & 16.8 & 11.3 & - \\
\hline L60_W4_D25_REF_1 & 27.0 & 0.44 & 19.8 & 8.3 & $\mathrm{D}$ \\
\hline L60_W4_D25_REF_2 & 30.8 & 0.46 & 22.5 & 9.5 & $\mathrm{D}$ \\
\hline L60_W4_D25_REF_3 & 26.3 & 0.51 & 19.2 & 8.1 & $\mathrm{D}$ \\
\hline L60_W4_D25_REF & $28.0(8.6 \%)$ & $0.47(7.7 \%)$ & 20.5 & 8.6 & - \\
\hline L60_W4_D25_WD_1 & 32.3 & 0.45 & 23.6 & 10.0 & $\mathrm{D}$ \\
\hline L60_W4_D25_WD_2 & 30.4 & 0.62 & 22.2 & 9.4 & $\mathrm{D}$ \\
\hline L60_W4_D25_WD_3 & 30.8 & 0.54 & 22.5 & 9.5 & $\mathrm{D}$ \\
\hline L60_W4_D25_WD & $31.2(3.2 \%)$ & $0.54(15.8 \%)$ & 22.8 & 9.6 & - \\
\hline L60_W8_D25_REF_1 & 30.6 & 0.76 & 22.3 & 8.8 & $\mathrm{D}$ \\
\hline L60_W8_D25_REF_2 & 30.7 & 0.66 & 22.4 & 8.8 & $\mathrm{D}$ \\
\hline L60_W8_D25_REF & $30.7(0.2 \%)$ & $0.71(10.0 \%)$ & 22.4 & 8.8 & - \\
\hline L60_W8_D25_WD_1 & 29.6 & 0.92 & 21.6 & 8.5 & $\mathrm{D}$ \\
\hline L60_W8_D25_WD_2 & 30.9 & 0.56 & 22.6 & 8.9 & $\mathrm{D}$ \\
\hline L60_W8_D25_WD & $30.3(3.0 \%)$ & $0.74(34.4 \%)$ & 22.1 & 8.7 & - \\
\hline L90 W4 D25 REF 1 & 36.5 & 0.98 & 17.8 & 7.5 & $\mathrm{~F}$ \\
\hline L90_W4_D25_REF_2 & 28.7 & 0.41 & 14.0 & 5.9 & $\mathrm{D}$ \\
\hline L90_W4_D25_REF & $32.6(16.9 \%)$ & $0.70(58.0 \%)$ & 15.9 & 6.7 & - \\
\hline L90_W4_D25_WD_1 & 37.7 & 1.06 & 18.4 & 7.8 & $\mathrm{C}$ \\
\hline L90_W4_D25_WD_2 & 27.6 & 0.73 & 13.5 & 5.7 & $\mathrm{C}$ \\
\hline L90_W4_D25_WD_3 & 39.9 & 0.95 & 19.5 & 8.2 & $\mathrm{C}$ \\
\hline L90_W4_D25_WD & $35.1(18.7 \%)$ & $0.91(18.4 \%)$ & 17.1 & 7.2 & - \\
\hline L60_W4_D25_REF*_1 & 27.4 & 0.67 & 20.0 & 8.5 & $\mathrm{D}$ \\
\hline
\end{tabular}

Notes: C: Concrete splitting; F: CFRP failure; D: debonding at epoxy/concrete interface 
Table 4: Numerical results

\begin{tabular}{llllllll}
\hline Series & $\tau_{m}(\mathrm{MPa})$ & $s_{m}(\mathrm{~mm})$ & $\alpha(-)$ & $\alpha^{\prime}(-)$ & $\operatorname{Err}(\%)$ & $F_{l, \text { num }} / F_{l, \text { exp }}(\%)$ & $s_{l, \text { num }} / s_{l, \text { exp }}(\%)$ \\
\hline L60_W4_D15_REF & 21.80 & 0.29 & 0.22 & 0.16 & 2.92 & -0.01 & 0.00 \\
L60_W4_D15_WD & 20.60 & 0.03 & 0.07 & 0.07 & 10.33 & 0.03 & -2.70 \\
L60_W8_D15_REF & 19.50 & 0.10 & 0.06 & 0.13 & 9.00 & -0.64 & 2.56 \\
L60_W8_D15_WD & 19.30 & 0.46 & 0.22 & 0.07 & 17.83 & 0.20 & 0.00 \\
L90_W4_D15_REF & 18.70 & 0.24 & 0.25 & 0.13 & 9.72 & 1.12 & 7.69 \\
L90_W4_D15_WD & 22.00 & 0.28 & 0.18 & 0.04 & 3.00 & -0.49 & 0.00 \\
\hline L60_W4_D25_REF & 21.50 & 0.13 & 0.17 & 0.08 & 1.18 & -0.25 & 0.00 \\
L60_W4_D25_WD & 23.80 & 0.18 & 0.14 & 0.10 & 3.07 & -0.07 & 0.00 \\
L60_W8_D25_REF & 23.00 & 0.32 & 0.31 & 0.11 & 2.24 & 0.10 & 5.26 \\
L60_W8_D25_WD & 21.80 & 0.34 & 0.24 & 0.11 & 8.00 & -0.05 & 5.33 \\
L90_W4_D25_REF & 19.40 & 0.27 & 0.18 & 0.11 & 6.65 & -0.97 & 0.00 \\
L90_W4_D25_WD & 18.20 & 0.26 & 0.22 & 0.11 & 5.19 & 0.29 & 0.00 \\
\hline L60_W4_D25_REF* & 20.20 & 0.45 & 0.21 & 0.07 & 8.69 & 0.66 & -7.79 \\
\hline
\end{tabular}




\section{$\underline{\text { List of Figures }}$}

Fig. 1: Specimen's geometry, test configuration and test setup.

Fig. 2: Typical pull-out force versus slip relationships.

Fig. 3: Failure modes: (a) Concrete splitting; (b) CFRP failure; (c) Debonding at adhesive/laminate interface.

Fig. 4: Strength variation due to wet-dry cycles.

Fig. 5: Comparison in the measurements obtained using an LVDT and the DIC method.

Fig. 6: Displacements, strains and distortional field registered in specimen L60_W4_D25_REF* by using the DIC method.

Fig. 7: Fish-spine resistant mechanism: (a) General scheme; (b) Optical microscopic view of the cracked region after pull-out test.

Fig. 8: Entities involved in the analytical model (series L90_W4_D15_REF at maximum pull-out force): (a) slip; (b) bond stress; (c) FRP strain; (d) FRP axial force.

Fig. 9: Comparison between some of the experimental and numerical pull-out force versus slip curves. 

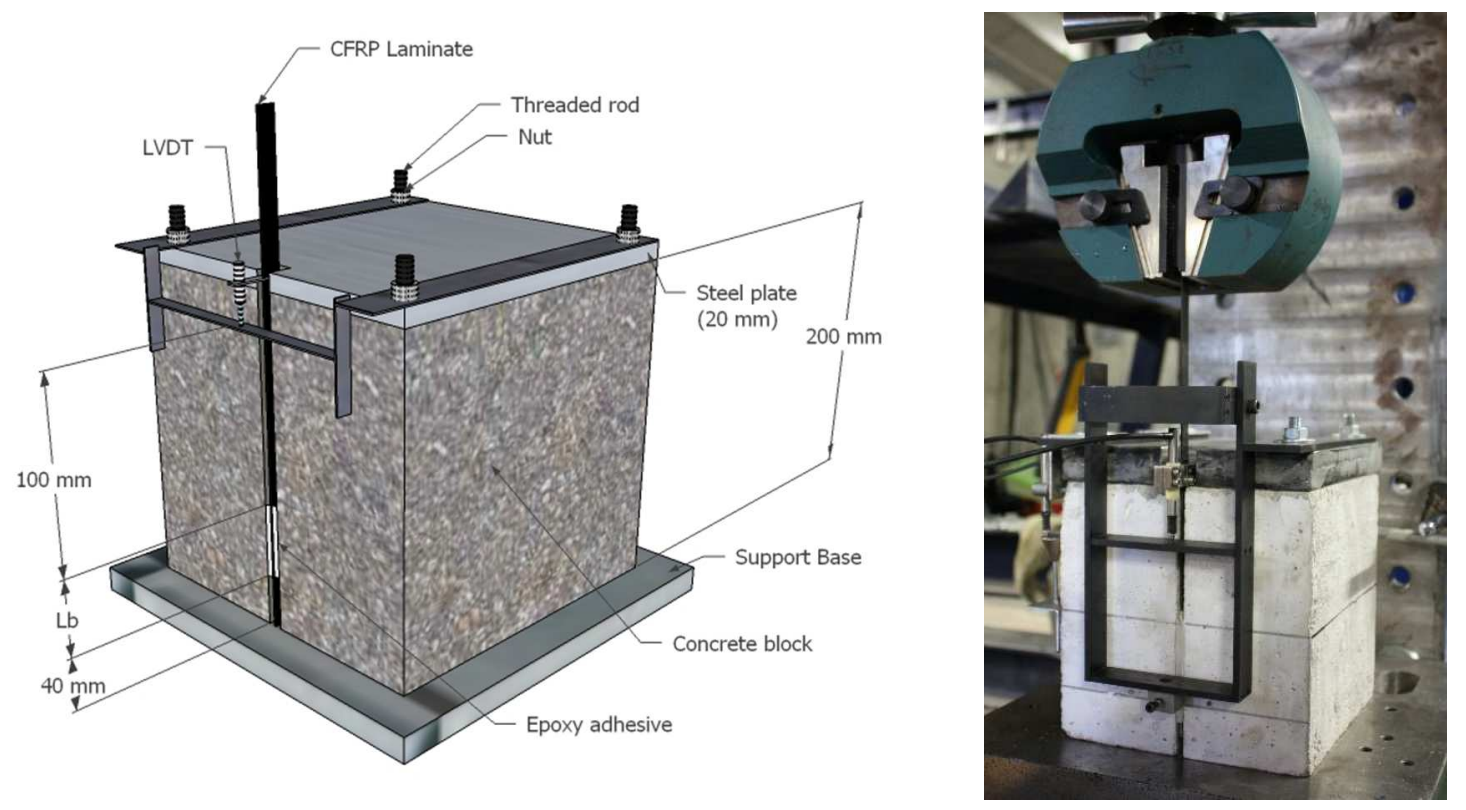

Fig. 1: Specimen's geometry, test configuration and test setup. 

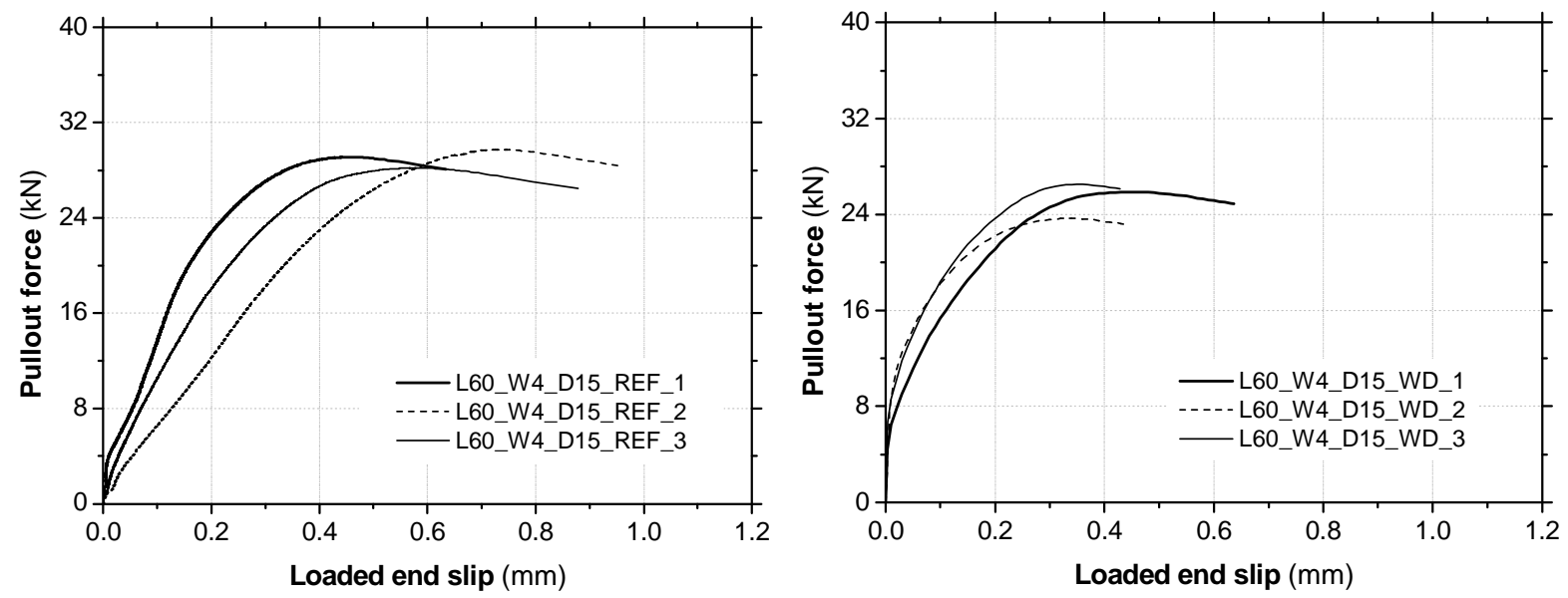

Fig. 2: Typical pull-out force versus slip relationships. 


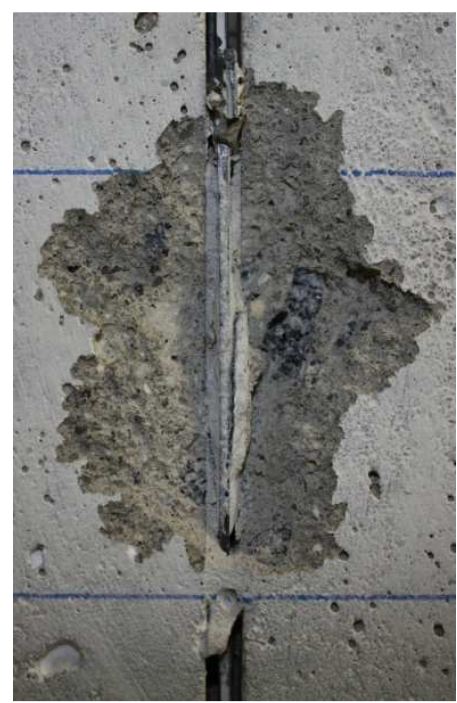

(a)

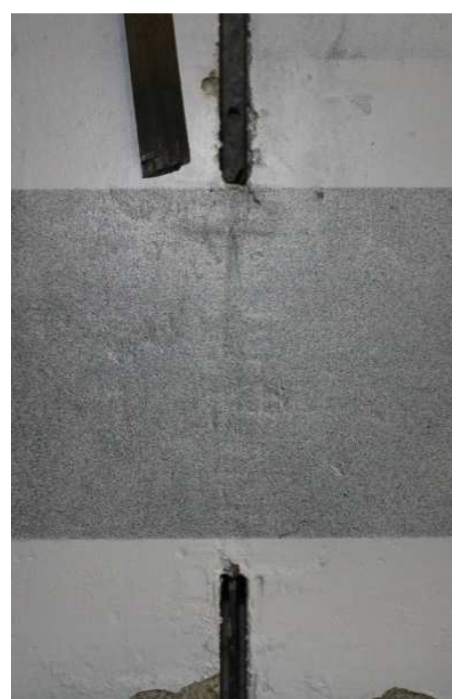

(b)

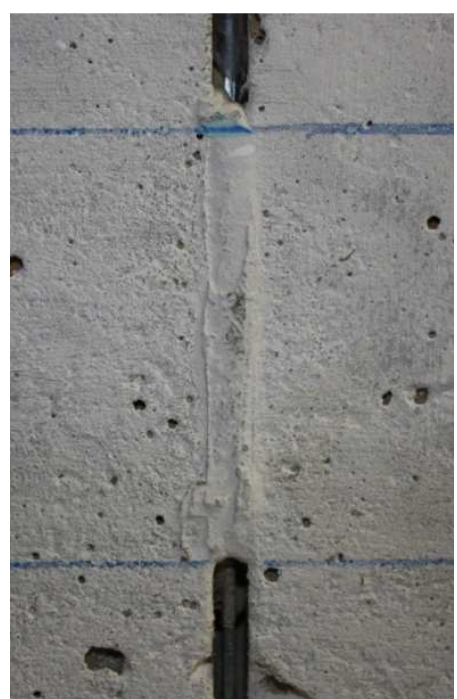

(c)

Fig. 3: Failure modes: (a) Concrete splitting; (b) CFRP failure; (c) Debonding at adhesive/laminate interface. 


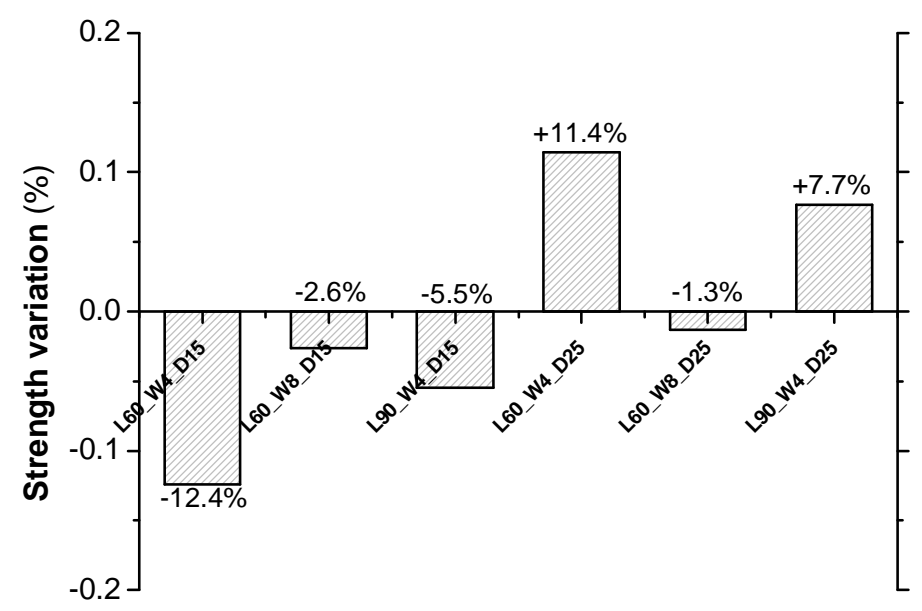

Fig. 4: Strength variation due to wet-dry cycles. 


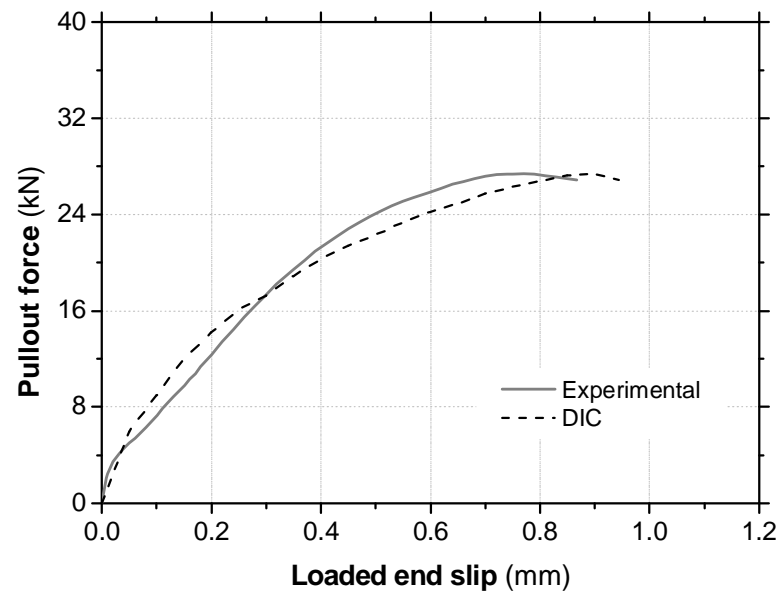

Fig. 5: Comparison in the measurements obtained using an LVDT and the DIC method. 


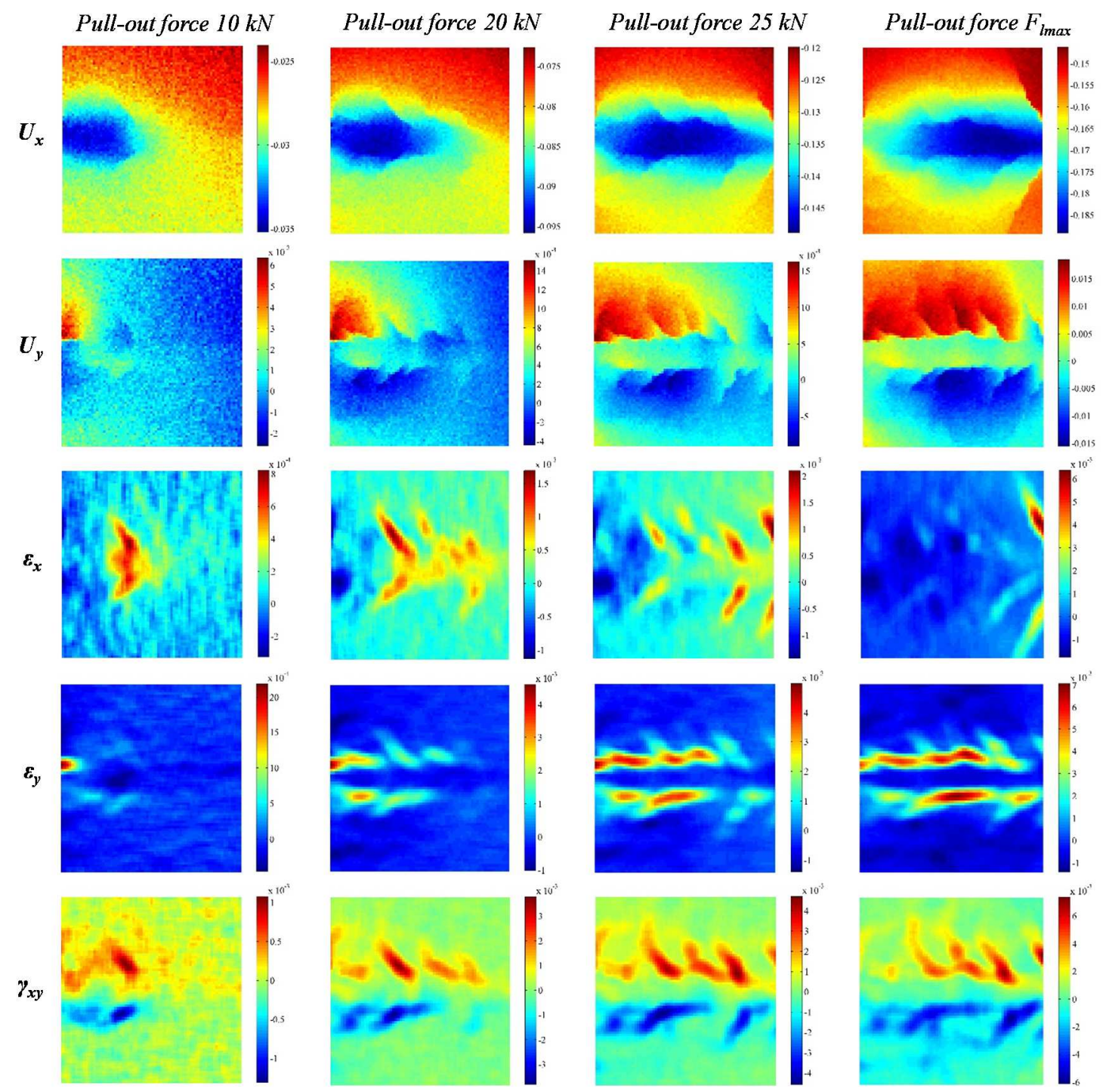

Fig. 6: Displacements, strains and distortional field registered in specimen L60_W4_D25_REF* by using the DIC method. 


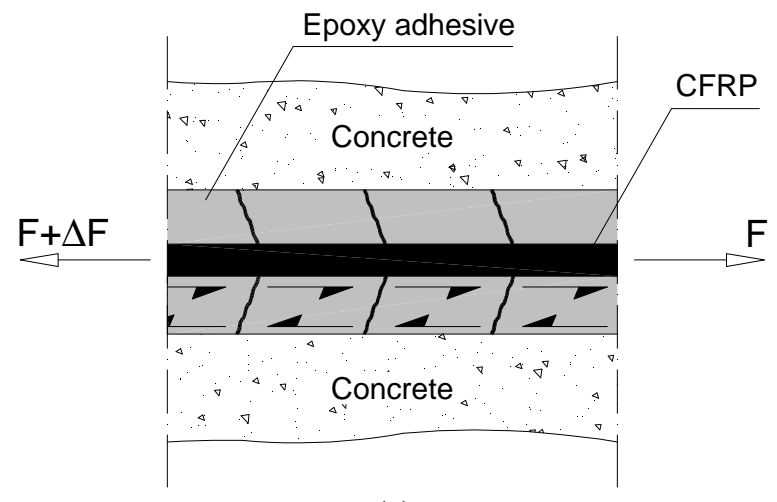

(a)

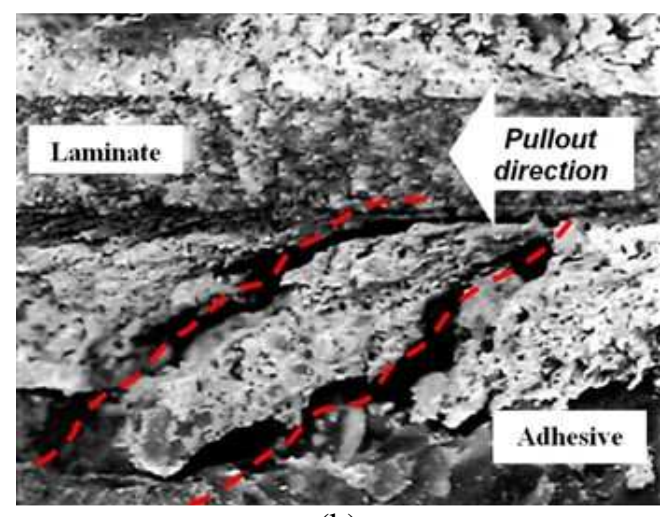

(b)

Fig. 7: Fish-spine resistant mechanism: (a) General scheme; (b) Optical microscopic view of the cracked region after pull-out test. 


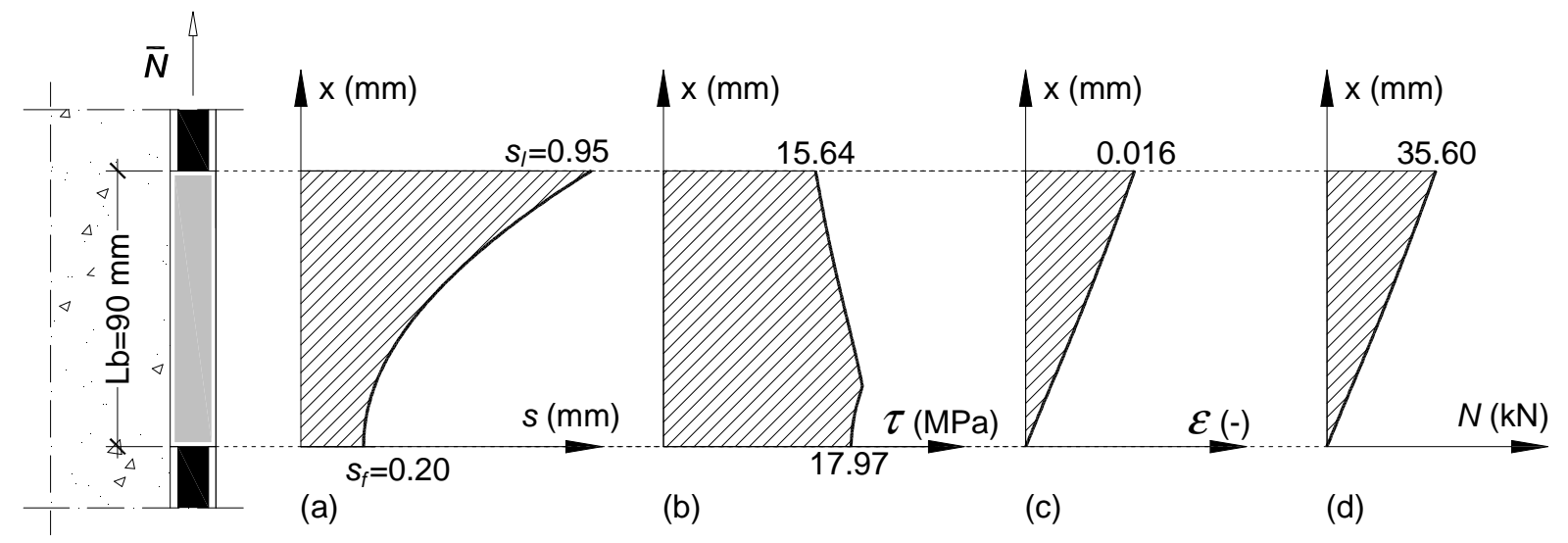

Fig. 8: Entities involved in the analytical model (series L90_W4_D15_REF at maximum pull-out force): (a) slip; (b) bond stress; (c) FRP strain; (d) FRP axial force. 

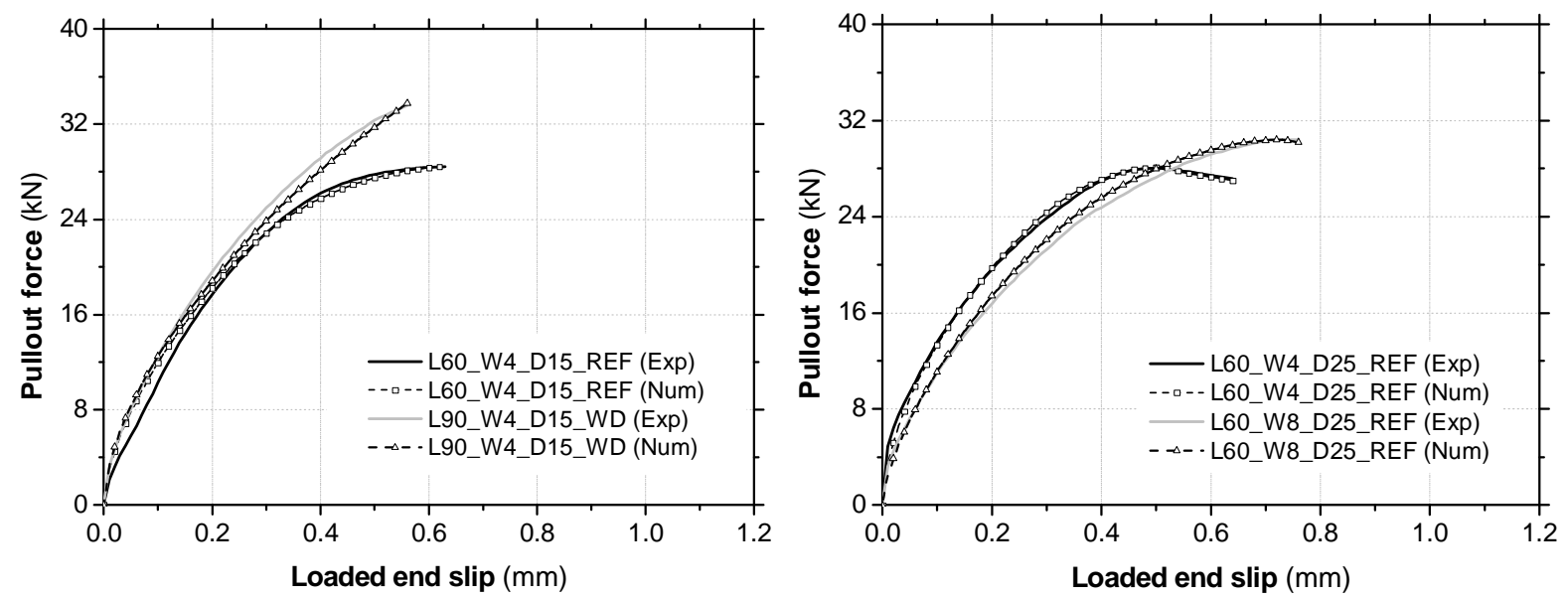

Fig. 9: Comparison between some of the experimental and numerical pull-out force versus slip curves. 